\title{
HEAVY WORK INUESTMENT AND PSYCHOPATHOLOGY: INTERNALIZING AND EXTERNALIZING DISORDERS AS ANTECEDENTS AND OUTCOMES
}

\author{
Yura Loscalzo $^{1^{*}}$ and Marco Giannini ${ }^{2}$ \\ ${ }^{1,2)}$ University of Florence, Florence, Italy
}

Please cite this article as:

Loscalzo, Y. and Giannini, M., 2020. Heavy Work Investment and Psychopathology: Internalizing and Externalizing Disorders as Antecedents and Outcomes. Amfiteatru Economic, 22(Special Issue No. 14), pp. $1301-1324$

DOI: $10.24818 / \mathrm{EA} / 2020 / \mathrm{S} 14 / 1301$

\section{Article History}

Received: 17 May 2020

Revised: 3 August 2020

Accepted: 5 September 2020

\begin{abstract}
Workaholism and work engagement are two types of Heavy Work Investment (HWI) that have been widely studied. However, the literature on the role of internalizing and externalizing disorders as antecedents and outcomes of these two types of HWI is scant. This study aims to analyze, through two path models, if workaholism and work engagement predict the main forms of psychopathology as evaluated through the Symptom Checklist90-R (SCL-90-R). Also, it analyzes if psychopathology and sensation seeking predict workaholism and work engagement to shed light on the internalizing and/or externalizing nature of workaholism. Besides the two path models, we also performed MANOVAs and Mann-Whitney tests to analyze differences in psychopathology and sensation seeking between workers with high and low levels of workaholism and work engagement, as well as between disengaged and engaged workaholics. The participants are 690 Italian workers (44.8\% males) with a mean age of $38.99 \pm 12.45$. The results showed that workaholism predicts higher psychopathology, while work engagement predicts lower psychological symptoms. Though, even if depression and boredom susceptibility negatively predict work engagement, it is also positively predicted by somatization. Moreover, workaholism is positively predicted by psychoticism only. Therefore, this study suggests that workaholism might be defined as the declination at work of a personality disorder, and that work engagement might be a coping strategy for workers experiencing somatic symptoms. Finally, preventive interventions should target both workaholism and work engagement, as high work engagement does not seem to protect engaged workaholics from psychological impairment.
\end{abstract}

Keywords: anxiety, depression, psychiatric disorders, workaholism, work addiction, work engagement, sensation seeking.

JEL Classification: I120

* Corresponding author, Yura Loscalzo - e-mail: yura.loscalzo@ gmail.com 


\section{Introduction}

This paper aims to shed light on the internalizing and/or externalizing nature of workaholism by analyzing the role of psychopathology as an antecedent and outcome of two types of Heavy Work Investment, that is, workaholism and work engagement. In the same line, we also evaluate if sensation seeking, as being linked to substance addictions (i.e., externalizing disorders), predicts workaholism. Moreover, based on Loscalzo and Giannini's (2017a) comprehensive model, we analyze if there are differences between engaged and disengaged workaholics in the variables of the study.

First, we present a review of the scant literature about workaholism, work engagement, and psychopathology. Next, we display the results of the two path analysis models we performed aiming to test if psychopathology is an outcome of workaholism and work engagement and if sensation seeking and psychopathology predict these two forms of Heavy Work Investment. Then, we present group-differences in psychopathology and sensation seeking between workers with high and low workaholism/work engagement, as well as between disengaged and engaged workaholics. Finally, the results are discussed with reference to the literature.

\section{Review of the scientific literature}

Loscalzo and Giannini (2017a) recently introduced in the literature a comprehensive workaholism model aiming to promote a coherent and unified understanding of this construct. More specifically, they suggested merging the Heavy Work Investment (HWI) framework (Snir and Harpaz, 2012) with the typology of different types of workaholic (i.e., disengaged and engaged workaholics). Hence, they recommended distinguishing among four types of worker, three of which are Heavy Work Investors (HWIs): disengaged workaholics, engaged workaholics, engaged workers, detached workers (this last one, not being an HWI). In addition, they pointed out the importance of distinguishing between disengaged and engaged workaholics when analyzing the antecedents and outcomes of workaholism, as they might have different relationships with the same variables, as recently supported by Spagnoli, et al. (2018). Another important point of Loscalzo and Giannini's (2017a) model is that, by adopting a clinical psychological perspective in reviewing workaholism literature, they defined workaholism as a clinical condition characterized by both externalizing (or addiction) and internalizing (or obsessive-compulsive) symptoms. Kardefelt-Winther (2015) stated that scholars should go beyond a priori addiction-related assumption when studying a potential new behavioral addiction in order to identify its real nature. In line with this, Loscalzo and Giannini (2017a) suggested taking a step back in workaholism's conceptualization and questioning its internalizing and/or externalizing nature since it still lacks a shared definition by the scientific community, despite being studied for 50 years. Finally, based on the review of the literature, they listed antecedents and outcomes by distinguishing between individual and situational ones. In this list, they included psychiatric disorders both in the individual antecedents and in the individual outcomes (in this case, they are labeled as "health impairment" as including both psychological and physical impairment).

The literature about workaholism, work engagement, and psychopathology is scant and mostly related to somatization, depression, and anxiety, that is, internalizing symptoms, or to mental health in general. Moreover, only a few studies included work engagement in the 
analysis of the relationships between HWI and psychopathology, and only two studies analyzed psychopathology as an antecedent of workaholism.

Andreassen, Ursin and Erisksen (2007) published the first study in this field. They administered the WorkBat (Spence and Robbins, 1992) for measuring workaholism (even if they did not include the Involvement subscale in their analyses), the Utrecht Work Engagement Scale (UWES; Schaufeli, et al., 2002) for work engagement, and the Subjective Health Complaints Inventory (SHC; Eriksen, Ihlebæk and Ursin, 1999) for measuring somatic and psychological issues (in this study, they did not include the SHC Allergy and Cold/Influenza scales). The SHC comprehends 29 items representing subjective health complaints (e.g., neck pain, headache, anxiety, sadness/depression); hence, its total score might be considered as a measure of somatization. Andreassen, et al. (2007) found a positive correlation between the WorkBat Drive subscale and both the Pseudoneurological complaints (which includes depression and anxiety items; $r=.23$ ) and the Gastrointestinal complaints $(r=.17)$; though, there was no correlation with the Musculoskeletal complaints. Concerning both the Enjoyment of Work (WorkBat) and the UWES subscales, the values of correlation are negative with all the SHC scales ( $r$ values ranging between .07 and .36). Finally, while the Drive WorkBat subscale is a positive predictor $(\beta=.23)$ of the SHC total score (or somatization), the Work Enjoyment subscale negatively predicts it $(\beta=-.14)$. Next, some of these relationships have been re-analyzed by Andreassen, et al. (2010), this time not including the UWES and using the SHC total score only. About the SHC, the authors reported using three of the SHC scales without specifying which ones; though, we might infer that they used the same three scales used in the previous study. Andreassen, et al. (2010) replicated the findings of Andreassen, et al.'s (2007) study. The Drive subscale showed a good and positive correlation with the SHC total score (or somatization), while the Enjoyment of Work subscale has a negative and low correlation with the SHC total score. Moreover, the Drive scale is a good and positive predictor of subjective health complaints (or somatization). Andreassen, et al. (2010) wrote that also the Involvement scale (included this time in the analysis) has a positive correlation with the SHC; though, through inspecting the table of correlations, the values are below .10 for both the full ( $r=.07$, not statistically significant) and short $(r=.09, p<.05)$ version of the WorkBat they used. The last study using the WorkBat is by Haar and Roche (2013). They analyzed psychopathology in the form of anxiety and depression, as evaluated through six adjectives to be rated on a 5-point Likert scale (Axtell, et al., 2002; Mullarkey, et al., 1999). They found that the Involvement and Drive WorkBat scales are positively correlated with both anxiety and depression ( $r$ values ranging between .44 and .61 ), while Enjoyment of Work is negatively related with both the psychopathology scales (-.35 and .41 , respectively). Moreover, when entered as predictors in the regression models, Involvement and Drive are positive predictors of anxiety (while Enjoyment of Work is a negative predictor). For depression, instead, Drive is a positive predictor, and Enjoyment of Work is a negative predictor; however, Involvement is not a statistically significant predictor.

In the literature, other studies have been conducted using different workaholism scales, that is the Work Addiction Risk Test (WART; Robinson, 1999), the Work Craving Scale (WCS; Wojdylo, et al., 2013), the DUWAS (Schaufeli, Shimazu and Taris, 2009), and the BWAS (Andreassen, et al., 2012). 
Bartcazk and Ogińska-Bulik (2012) conducted the first study using the WART. For psychopathology, they administered the General Health Questionnaire (GHQ-28; Goldberg and Hillier, 1979) that allows evaluating somatic symptoms, anxiety/insomnia, social dysfunction, and symptoms of depression. Concerning the three psychopathology scales (even if anxiety includes insomnia), they found good and positive correlations with all the scales ( $r$ values ranging between .30 and .44). However, for assessing the predictive power of workaholism on psychopathology, they used the WART subscales only, except for depression (for which they used the total score because the subscales were not statistically significant). For depression, workaholism is a positive predictor $(\beta=.34)$. Next, Wojdylo, et al. (2013) included both the WCS and the WART for measuring workaholism, and the Beck Depression Inventory (BDI; Beck, et al., 1961) for measuring depression. Their results showed that both the WART and WCS total scores have positive correlations with the BDI (though, the correlation is higher for the WART). Moreover, while the WART predicts depression ( $\beta$ value of .30), WCS scales do not predict depression at a statistically significant level. Finally, Wojdylo, et al. (2013), using the WCS and the GHQ-28 total score, found that workaholism is associated with impaired general mental health status. In another study, including the GHQ-28 total score and both the WCS and the UWES, Wojdylo, et al. (2014) found opposite relationships between workaholism, work engagement, and general mental health status. Through correlation and path model analyses, they found that workaholism is associated with poor mental health, while work engagement is associated with good mental health.

About studies using the DUWAS, Schaufeli, et al. (2008) conducted a research using a workaholism instrument that (referring to their description) seems to be a preliminary version of the DUWAS, and included two scales: Working Excessively and Drive. Moreover, they administered the UWES for measuring work engagement, and the FourDimensional Symptom Questionnaire (4DSQ; Terluin, et al., 2004) for evaluating distress, depression, anxiety, and psychosomatic complaints. Concerning the three psychopathology scales, correlation analyses showed that only the Drive scale correlates positively with all of them, while Working Excessively did not correlate with them. About work engagement, all the three UWES subscales (Vigor, Dedication, Absorption) correlate negatively with psychopathology, even if for absorption they are not statistically significant (except for depression) and near to zero. Moreover, concerning regression analysis, Schaufeli, et al. (2008) did not find significant predictors for anxiety, while Vigor negatively predicts depression. Though, both Vigor and Dedication positively predict Psychosomatic Complaints, as well as Drive, and (to a lesser extent) Working Excessively. However, all the $\beta$ values are low (ranging between .09 and .15). Moreover, Schaufeli, et al. (2008) suggest that the positive predictive value of work engagement on psychosomatic complaints is probably due to a statistical artifact. Concerning the DUWAS in its final form, Matsudaira, et al. (2013) used this scale in order to differentiate between low, average, and high workaholics; next, they distinguished between participants having (or not) depressive mood using a cut-off based on the total score of the Short Form Health Survey (SF-36; Ware and Sherbourne, 1992). They found support for an association between workaholism and depression since the average and high workaholics have higher odds for depressive mood as compared to low workaholics. Finally, Nie and Sun (2016), using the Self-Rating Depression Scale (Zung, 1986), found a good and positive correlation with the DUWAS $(r=.40)$. Moreover, they also found a good and positive (direct) 
predictive value of workaholism for depression, which is still good when burnout is entered in the mediation model.

Finally, three studies have used the BWAS. Two studies also included an analysis of psychiatric disorders as antecedents (instead of outcomes) of workaholism. The first study is by Andreassen, et al. (2016). It evaluates as potential antecedents of workaholism the following psychiatric disorders: Attention-Deficit/Hyperactive Disorder (ADHD) through the Adult ADHD Self-Report Scale (ASRS-Version 1.1; Kessler, et al., 2005); Obsessive-Compulsive Disorder (OCD) through the Obsession-Compulsive Inventory-Revised (OCI-R; Foa, et al., 2002), which assesses checking, ordering, neutralizing, washing, obsessing, and hoarding symptoms; anxiety and depression using the Hospital Anxiety and Depression Scale (HADS; Zigmond and Snaith, 1983). In line with previous studies, Andreassen, et al. (2016) found positive correlations with all the psychopathology scales, with values ranging between .16 and .36. Next, regression analysis showed that ADHD $(\beta=.20)$ and anxiety $(\beta=.17)$ predict workaholism, while depression is just a very low predictor $(\beta=.06)$. The OCI-R scales (that is different types of compulsions and obsessions) predict workaholism with $\beta$ values that are very low $(<.08)$ and, in some cases, not statistically significant. Finally, analyzing the relationship between the presence/absence of workaholism and the four clinical disorders, they showed that workaholics have higher psychopathology scores than non-workaholics. Next, Atroszko, et al. (2017) further evaluated the relationship between workaholism, ADHD, and depression. Though, while they used the ASRS-Version 1.1 for ADHD, they did not include a self-report scale for depression. Instead, they report having asked about health through questions concerning current or previously diagnosed diseases, including depression. Hence, they classified participants in having clinical or non-clinical levels of depression based on their answers. The correlation analyses highlighted a positive correlation with ADHD and a lower correlation with depression $(r=.12)$. In line with the higher correlation of ADHD with the BWAS, workaholism is predicted by ADHD, but not by depression. Also, Atroszko, et al. (2018) found that workaholics are more likely to report clinical levels of ADHD and depression than non-workaholics. Finally, Andreassen, Pallesen, and Torsheim (2018), in a study mostly related to the role of workaholism in mediating the relationship between workrelated stressors and health outcomes, found that workaholism has positive correlations with somatic symptoms $(r=.40)$, anxiety/insomnia $(r=.46)$, and depression $(r=.23)$, as evaluated through the GHQ-28.

In sum, previous studies have shown an association between workaholism and somatization (Andreassen, et al., 2007, 2010, 2018; Bartcazk and Ogińska-Bulik, 2012), anxiety (Andreassen, et al., 2016, 2018; Bartcazk and Ogińska-Bulik, 2012; Haar and Roche, 2013), depression (Bartcazk and Ogińska-Bulik, 2012; Haar and Roche, 2013; Matsudaira, et al., 2013; Wojdylo, et al., 2013; Andreassen, et al., 2016, 2018; Nie and Sun, 2016; Atroszko, et al., 2017), ADHD (Andreassen, et al., 2016; Atroszko, et al., 2018), and OCD symptoms (Andreassen, et al., 2016). Moreover, the two studies analyzing psychopathology as a predictor of workaholism found that ADHD and anxiety predict workaholism (Andreassen, et al., 2016; Atroszko, et al., 2018), while depression and OCD do not predict it, or predict it with a very low $\beta$ value (Andreassen, et al., 2016, Atroszko, et al., 2018). About work engagement (or work enjoyment), instead, the studies generally found that it is associated with better mental health: lower somatization (Andreassen, et al., 2007, 2010), anxiety and depression (Haar and Roche, 2013), and better mental health in general (Wojdylo, et al. 2014). Though, Scahufeli, et al. (2008), besides finding a negative correlation between work engagement and somatization, also found that Vigor and 
Dedication positively predict psychosomatic complaints. Even if they concluded that this result might be due to a statistical artifact, it is interesting to note that Shimazu, et al. (2018) found a curvilinear relationship between work engagement and psychological distress in the short term. Initially, there is a positive effect of work engagement on mental health, though this effect disappears at an intermediate level of work engagement, and a negative effect on mental health arises at higher levels. Though, Shimazu, et al. (2018) highlighted that although high levels of work engagement may harm mental health in the short term, this negative effect disappears, and it becomes positive, in the long term.

Based on this review of the literature, the present study aims to shed light on the role of both internalizing and externalizing disorders as antecedents and outcomes of two forms of HWI, that is workaholism and work engagement. The literature about the relationship between psychiatric disorders and these two forms of HWI is scarce and does not take into account all the most major internalizing and externalizing psychiatric disorders, focusing mainly on somatization, anxiety, and depression. Moreover, except for Andreassen, et al. (2016) and Atroszko, et al. (2018), there are no studies that analyzed psychiatric disorders as antecedents of workaholism. Finally, no studies analyzed all the main internalizing and externalizing disorders as antecedents of workaholism in the same research. The knowledge that might arise from our study is of vital importance for shedding light on the real nature of workaholism, with implications for preventive and clinical interventions. In line with this, we also analyzed the role of sensation seeking as another potential antecedent of workaholism.

Sensation seeking is a personality trait that is characterized by the seeking of experiences and sensations that are varied, novel, complex, and intense, as well as by the willingness to take risks for getting these experiences, including physical, social, financial and legal issues (Zuckerman, 1994). This personality trait has been consistently linked to the use and abuse of psychoactive substances, such as drugs (Jaffe and Archer, 1987; Adams, et al., 2012; Zhornitsky, et al., 2012; Ersche, et al., 2015; Linden-Carmichael, et al., 2016;), alcohol (Hittner and Swickert, 2006; Stautz and Cooper, 2013; Meil, et al., 2016; Rogers, et al., 2018), and marijuana (Miles, et al., 2001; Crawford, et al., 2004; Keyes, et al., 2015; Meil, et al., 2016). Though, concerning behavioral addictions and, more specifically, gambling disorder (that is the only behavioral addiction formally recognized by the Diagnostic and Statistical Manual of Mental Disorder, $5^{\text {th }}$ edition - DSM-5; APA, 2013), the results about the relationship with sensation seeking are not consistent. Some studies reported higher sensation seeking in gambling disorder, at least in some components of this personality trait (Blaszczynski, Wilson, and McConaghy, 1986; Kuley and Jacobs, 1988; Breen and Zuckerman, 1999; Powell and Hardoon, 1999). However, other studies found a negative relationship between gambling and sensation seeking, or even no relationships (Allcock and Grace, 1988; Coventry and Brown, 1993; Bonnaire, Lejoyeux, and Dardennes, 2004; SaezAbad and Bertolin-Guillen, 2008; Fortune and Goodie, 2010). Finally, MacLaren, et al. (2011)'s meta-analysis showed that there is no evidence of higher sensation seeking in gambling disorder. In line with this, Müller, et al. (2016) recently showed that sensation seeking does not predict gambling disorder.

Hence, in order to shed light on the internalizing and/or externalizing nature of workaholism, we added sensation seeking as a predictor of workaholism, since it is a personality trait consistently linked to substance-related addictions (i.e., externalizing disorders), even if its relationship with gambling disorder is not clear yet. In order to have a 
clear understanding of the relationship between workaholism and sensation seeking, also in light of the different relationships that the literature showed between its different components and the same behavior (Giannini and Loscalzo, in press), we analyzed sensation seeking in its four components: Thrill and Adventure Seeking, Experience Seeking, Disinhibition, and Boredom Susceptibility (Zuckerman, 1994).

In conclusion, this study aims to shed light on the real nature of workaholism by means of a thorough analysis of internalizing and externalizing psychopathology as both an antecedent and outcome of workaholism (and work engagement). In line with this primary objective, we also aim to analyze sensation seeking as a potential antecedent of workaholism and work engagement. Finally, given the mixed findings about the relationship between workaholism and time spent working (e.g., Andreassen, et al., 2010; Haar and Roche, 2013; Wojdylo, et al., 2013, 2014), we also include this variable as an additional outcome. Since the literature concerning workaholism, work engagement, and psychopathology is scant, and many of the major internalizing and externalizing disorders have not been explored so far, we did not posit specific hypotheses, even though we generally expect (based on the previous review of the literature) that workaholism predicts higher psychopathology (e.g., Andreassen, et al., 2007; Bartcazc and Ogińska-Bulik, 2012; Wojdylo, et al., 2013; Loscalzo and Giannini, 2017a), while work engagement predicts lower levels of psychological disorders (e.g., Andreassen, et al., 2007; Haar and Roche, 2013). About sensation seeking, there are no studies concerning workaholism, and the results about gambling disorder are inconclusive; hence, our study is explorative concerning this variable. This study is of critical importance since- taking a step back in the analysis of workaholism, as suggested by Loscalzo and Giannini (2017a), could help to get a better understanding of both workaholism and work engagement, namely two different types of HWI. This could also have important implications for preventive and clinical purposes. As previously stated by Loscalzo and Giannini (2017a), understanding the real nature of the negative type of HWI (i.e., workaholism) might help better define interventions based on previous studies about disorders that are similar to workaholism.

\section{Research methodology}

\subsection{Participants}

We gathered 690 workers ( $44.8 \%$ males, 55.2\% females) aged between 19 and 71 years (M $=38.99, \mathrm{SD}=12.45)$. The majority of the participants lives in Tuscany $(65.3 \%)$, even if all of Italy is represented. Due to the length of the instruments used for evaluating psychopathology (90 items) and sensation seeking (40 items), we first administered the psychopathology scale only to the first sample of participants $(n=324)$, and then included the scale for evaluating sensation seeking in the questionnaire $(n=366)$.

The first sample is made up by 324 workers ( $44.4 \%$ males, $55.6 \%$ females) aged between 19 and 71 years old $(\mathrm{M}=37.41, \mathrm{SD}=12.74)$. Most of them live in Tuscany $(83.2 \%)$; concerning their civil status, $37.0 \%$ is married, followed by singles $(23.5 \%)$, engaged $(17.9 \%)$, and cohabitant $(16.4 \%)$. The others are separated or divorced. About their level of education, the $.3 \%$ reported having attended primary school only, the $11.7 \%$ have finished the first grade of secondary school, and the majority of participants had a diploma of secondary grade of secondary school (42.3\%). There are also people with a bachelor's $(14.5 \%)$ or Master's (12.7\%) degree, and some with post-graduate studies (e.g., Ph.D. or 
specializations; $18.5 \%)$. About half of the participants reported that their current job is coherent with their school's studies (54.9\%) and usually work in their days off or outside working hours (54\%). About their contract, the majority has a permanent contract (50.9\%), though there are also people with fixed-term contracts $(21.3 \%)$ and autonomous workers (19.8\%). The others reported having other types of contract (e.g., contract on call). Moreover, $78.1 \%$ of the participants work full-time, while $21.9 \%$ work part-time. Finally, there are different kinds of workers: employees $(42.3 \%)$, hand workers $(17.6 \%)$, managers $(10.2 \%)$, independent professional workers $(9.9 \%)$, autonomous workers $(5.9 \%)$, and entrepreneurs $(4.3 \%)$, other types of workers $(9.8 \%)$. This sample has been used for the analysis concerning psychopathology as an outcome of workaholism and work engagement.

The second sample, instead, is made up of 366 workers ( $45.1 \%$ males, $54.9 \%$ females) aged between 20 and 66 years old $(\mathrm{M}=40.39, \mathrm{SD}=12.03)$. About half of the participants live in Tuscany $(49.5 \%)$. Concerning their civil status, $36.9 \%$ is married, followed by singles $(21.3 \%)$, cohabitant $(16.9 \%)$, and engaged $(13.7 \%)$. The others are separated, divorced, or widows. About their level of education, the $.3 \%$ reported having attended primary school only, the $14.5 \%$ have finished the secondary school of first grade, and the majority of participants have a diploma of secondary school of second grade (47\%). There are also people with a bachelor's $(12.0 \%)$ or Master's $(17.5 \%)$ degree, and some with post-graduate studies (8.7\%). Moreover, $46.4 \%$ of the participants stated that their current job is coherent with their school's studies, and $52.5 \%$ of workers usually work in their days off or outside working hours. About their contract, the majority has a permanent contract (57.1\%); next, there are autonomous workers (20.8\%) and workers with fixed-term contracts (16.7\%). The others reported having other types of contract. About working full-time or part-time, the majority of participants work full-time (80.3\%). Finally, there are different kinds of workers also in this sample. The majority of participants are employees $(47.5 \%)$ and hand workers $(20.8 \%)$. Next, there are independent professional workers $(6.8 \%)$, autonomous workers (7.7\%), entrepreneurs (7.4\%), and managers (1.4\%), and other types of worker $(8.4 \%)$. This sample has been used for the analysis related to psychopathology and sensation seeking as antecedents of workaholism and work engagement.

\subsection{Materials}

\subsubsection{Work-related Inventory (WI-10; Loscalzo and Giannini, 2019a)}

It is a 10-item (two filler items) self-report instrument that Loscalzo and Giannini (2019a) created based on their comprehensive model (Loscalzo and Giannini, 2017a) in order to evaluate both Workaholism and Work Engagement. The WI-10 has a good factor structure $(\mathrm{CFI}=.97$; GI $=.97$; RMSEA $=.06)$, satisfactory internal reliability, and good convergent and divergent validity (Loscalzo and Giannini, 2019a). In addition, they defined the cut-off scores for screening four kinds of worker: disengaged workaholic, engaged workaholic, engaged worker, detached worker. More specifically, Loscalzo and Giannini (2019a) calculated the $40^{\text {th }}$ and $60^{\text {th }} T$ score for the WI-10 scales, and next looked for the corresponding raw scores in order to establish the Italian cut-off scores for high/low Workaholism/Work Engagement. Finally, the WI-10 includes a head-sheet asking about school education and working habits (including hours per week usually spent working, which we included in the present study as an outcome variable). The participants answer 
each item through a 5-point Likert scale ranging between 1 (Completely disagree) and 5 (Completely agree).

\subsubsection{Symptom Check List-90-R (SCL-90-R; Derogatis, 1994)}

It is a 90-item self-report instrument that allows evaluation of both internalizing (e.g., anxiety, depression) and externalizing (e.g., aggressiveness, impulsivity) symptoms. The SCL-90-R allows an assessment of nine clinical symptoms: Somatization (SOM, or the distress arising from bodily perceptions); Obsessive-Compulsive (O-C, namely the typical obsessive-compulsive symptoms); Interpersonal Sensitivity (I-S, or feeling inadequate and inferior to others); Depression (DEP, including also a lack of motivation); Anxiety (ANX, evaluating both anxiety symptoms and tension); Hostility (HOS, that addresses negative affect, irritability, and aggressiveness); Phobic Anxiety (PHOB, or persistent fears of specific situations); Paranoid Ideation (PAR, namely hostility, suspiciousness, projection, and fear of loss of autonomy); Psychoticism (PSY, evaluating symptoms ranging from mild interpersonal alienation to psychosis). In the Italian version, the person responds to each item using a 5-point Likert scale ranging from 1 (Not at all) to 5 (Extremely).

\subsubsection{Sensation Seeking Scale form V (SSS-V; Zuckerman, 1994; Zuckerman, Eysenk,} and Eysenk, 1978)

The SSS-V is a 40-item self-report scale for the evaluation of sensation seeking through four scales (each one made by 10 items): Thrill and Adventure Seeking - or the desire to engage in sport or physical activities involving danger or speed; Experience Seeking - or the seeking of new experiences involving mind and senses, as well as a lifestyle which is not conformist; Disinhibition - that is the interest in social and sexual activities that are characterized by disinhibition; Boredom Susceptibility, or the aversion toward routine and repetitive activities. The participant answers each item by choosing between two sentences (A and B), the one that applies the best to him/her. Each item is then scored as " 1 " if the sentence represents sensation seeking. For the other sentence, the score is " 0 ". To the best of our knowledge, there is not an Italian validation of this scale on an adult population. Though, the SSS-V has already been used in Italian youths by Tonetti, et al. (2010), and it allows us to evaluate sensation seeking in its four dimensions. In the present sample, alpha values are not good in most of the cases: Thrill and Adventure Seeking $(\alpha=.77)$, Experience Seeking $(\alpha=.56)$, Disinhibition $(\alpha=.59)$, Boredom Susceptibility $(\alpha=.58)$.

\subsection{Procedure}

First, we asked approval for this research to the Ethical Committee of the University of Florence. Then, we created an online questionnaire containing some questions about personal data (e.g., gender, age), the WI-10, the SCL-90-R, and - for the second sample only - the SSS-V. We recruited participants through direct contact in their workplace and through the spread of the invitation to the research in social networks (the questionnaire itself has not been spread in social networks), aiming to reach participants outside Tuscany. In both cases, people filled the questionnaire online. On the first page of the questionnaire, we wrote all the information required by the Informed Consent, and we asked participants to check the box stating that by filling the questionnaire on the next pages, they agreed to take part in the research. 


\subsection{Data Analysis}

We performed analyses using SPSS.26 and AMOS.22.

First, we analyzed the zero-order correlations of the variables included in this study on the total sample $(n=690)$. Then, in order to analyze psychopathology (and time invested in work) as an outcome of workaholism and work engagement, we tested a Structural Equation Model (SEM) and, more specifically, a path analysis (Maximum Likelihood estimate method), on the first sample $(n=324)$. Next, we tested another path analysis model on the second sample $(n=366)$ in order to evaluate the role of psychopathology and sensation seeking in predicting workaholism and work engagement. In order to evaluate the fit of the models, we used the following indices and cut-off values: $\chi^{2} / \mathrm{df}$ ratio, which indicates a good fit if its value is less than 3 (Byrne, 2001); Goodness of Fit Index (GFI) and Comparative Fit Index (CFI), whose cut-offs are: <.90 lack of fit, .90-.95 good fit, >.95 excellent fit (Hu \& Bentler, 1999); and, Root Mean Square Error of Approximation (RMSEA), where a value below .05 indicates excellent fit, while values between .05 and .08 indicate an acceptable fit (Reeve, et al., 2007).

Next, we analyzed if there are differences between high and low workaholism/work engagement in the psychopathology and sensation seeking scales by means of MANOVAs. Finally, we analyzed if there are differences between disengaged and engaged workaholics in the psychopathology and sensation seeking scales through Mann-Whitney tests. The two types of workaholics have been created referring to the WI-10 cut-off values for Italian workers (Loscalzo \& Giannini, 2019a).

\section{Results}

\subsection{Internalizing and Externalizing Disorders as Outcomes of HWI}

As a first step, we analyzed the zero-order correlations among all the variables included in the two path analysis models (Table 1 shows the results of these analyses). This analysis highlighted a positive association between workaholism and both internalizing and externalizing disorders, while the correlation between work engagement and psychopathology is negative. About sensation seeking, there is only one statistically significant correlation, that is, the negative one between work engagement and Boredom Susceptibility. Finally, working hours do not correlate with workaholism, and the positive correlation with work engagement is very low $(r=.08)$.

Table no. 1. Zero-order correlations among study variables $(n=690$ for SCL-90-R scale; $n=366$ for SSS-V scales).

\begin{tabular}{|l|l|l|l|l|l|l|l|l|l|l|l|l|l|l|l|l|l|}
\hline & $\mathbf{1}$ & $\mathbf{2}$ & $\mathbf{3}$ & $\mathbf{4}$ & $\mathbf{5}$ & $\mathbf{6}$ & $\mathbf{7}$ & $\mathbf{8}$ & $\mathbf{9}$ & $\mathbf{1 0}$ & $\mathbf{1 1}$ & $\mathbf{1 2}$ & $\mathbf{1 3}$ & $\mathbf{1 4}$ & $\mathbf{1 5}$ & $\mathbf{1 6}$ & $\mathbf{1 7}$ \\
\hline 1.WH & - & & & & & & & & & & & & & & & & \\
\hline 2.WE & $.31^{\circ}$ & - & & & & & & & & & & & & & & & \\
\hline 3.SOM & $.19^{\circ}$ & $-.09^{*}$ & - & & & & & & & & & & & & & & \\
\hline 4.O-C & $.24^{\circ}$ & $-.17^{\circ}$ & $.65^{\circ}$ & - & & & & & & & & & & & & & \\
\hline 5.I-S & $.23^{\circ}$ & $-.17^{\circ}$ & $.57^{\circ}$ & $.75^{\circ}$ & - & & & & & & & & & & & & \\
\hline 6.DEP & $.25^{\circ}$ & $-.20^{\circ}$ & $.70^{\circ}$ & $.83^{\circ}$ & $.78^{\circ}$ & - & & & & & & & & & & & \\
\hline
\end{tabular}




\begin{tabular}{|l|l|l|l|l|l|l|l|l|l|l|l|l|l|l|l|l|l|}
\hline & $\mathbf{1}$ & $\mathbf{2}$ & $\mathbf{3}$ & $\mathbf{4}$ & $\mathbf{5}$ & $\mathbf{6}$ & $\mathbf{7}$ & $\mathbf{8}$ & $\mathbf{9}$ & $\mathbf{1 0}$ & $\mathbf{1 1}$ & $\mathbf{1 2}$ & $\mathbf{1 3}$ & $\mathbf{1 4}$ & $\mathbf{1 5}$ & $\mathbf{1 6}$ & $\mathbf{1 7}$ \\
\hline 7.ANX & $.28^{\circ}$ & $-.15^{\circ}$ & $.77^{\circ}$ & $.76^{\circ}$ & $.72^{\circ}$ & $.82^{\circ}$ & - & & & & & & & & & & \\
\hline 8.HOS & $.20^{\circ}$ & $-.13^{\circ}$ & $.59^{\circ}$ & $.63^{\circ}$ & $.66^{\circ}$ & $.69^{\circ}$ & $.69^{\circ}$ & - & & & & & & & & & \\
\hline 9.PHOB & $.25^{\circ}$ & $-.13^{\circ}$ & $.59^{\circ}$ & $.54^{\circ}$ & $.59^{\circ}$ & $.57^{\circ}$ & $.70^{\circ}$ & $.54^{\circ}$ & - & & & & & & & & \\
\hline $\mathbf{1 0 . P A R}$ & $.23^{\circ}$ & $-.16^{\circ}$ & $.53^{\circ}$ & $.64^{\circ}$ & $.73^{\circ}$ & $.68^{\circ}$ & $.65^{\circ}$ & $.68^{\circ}$ & $.52^{\circ}$ & - & & & & & & & \\
\hline $\mathbf{1 1 . P S Y}$ & $.27^{\circ}$ & $-.15^{*}$ & $.65^{\circ}$ & $.76^{\circ}$ & $.80^{\circ}$ & $.78^{\circ}$ & $.79^{\circ}$ & $.68^{\circ}$ & $.65^{\circ}$ & $.74^{\circ}$ & - & & & & & & \\
\hline 12.BS & -.00 & $-.14^{*}$ & -.04 & .05 & .05 & -.01 & .01 & $.14^{* *}$ & .03 & $.18^{\circ}$ & .07 & - & & & & & \\
\hline 13.DIS & -.02 & -.07 & -.08 & .09 & -.04 & -.04 & -.03 & .06 & $-.11^{*}$ & .03 & -.04 & $.48^{\circ}$ & - & & & & \\
\hline 14.ES & -.05 & .02 & -.09 & .02 & -.09 & -.05 & -.06 & -.06 & $-.20^{\circ}$ & -.10 & -.04 & $.22^{\circ}$ & $.47^{\circ}$ & - & & & \\
\hline 15.TAS & -.05 & .05 & $-.11^{*}$ & -.03 & $-.14^{* *}$ & -.09 & $-14^{* *}$ & -.04 & $-.22^{\circ}$ & -.04 & -.08 & $.22^{\circ}$ & $.43^{\circ}$ & $.46^{\circ}$ & - & & \\
\hline 16.SSS & -.05 & -.04 & $-.11^{*}$ & .04 & -.09 & -.07 & -.09 & .03 & $-.18^{\circ}$ & .02 & -.03 & $.62^{\circ}$ & $.80^{\circ}$ & $.72^{\circ}$ & $.78^{\circ}$ & - & \\
\hline 17.HrS & -.05 & $.08^{*}$ & -.01 & -.04 & -.03 & -.01 & -.00 & .03 & $-.09^{*}$ & -.05 & -.07 & -.03 & .10 & $.15^{* *}$ & $.15^{* *}$ & $.14^{*}$ & - \\
\hline
\end{tabular}

Note: $\mathrm{WH}=$ Workaholism (Work-related Inventory); WE $=$ Work Engagement (Workrelated Inventory); $\mathrm{SOM}=$ Somatization; O-C = Obsessive-Compulsive; I-S = Interpersonal Sensitivity; DEP = Depression; $\mathrm{ANX}=$ Anxiety $; \mathrm{HOS}=$ Hostility PHOB $=$ Phobic Anxiety; PAR = Paranoid Ideation; PSY = Psychoticism. All the psychopathology scales are from the Symptoms Checklist 90 Revised (SCL-90-R); BS = Boredom Susceptibility; DIS = Disinhibition; ES = Experience Seeking; TAS = Thrill and Adventure Seeking; SSS = Sensation Seeking total score; All the sensation seeking scales are from the Sensation Seeking Scale form V (SSS-V); Hrs $=$ Hours of work per week ${ }^{\circ}=p \leq .001 ; *^{*}=p \leq .01$; $* p \leq .05$.

Next, on the first sample $(n=324)$, we tested our first model, in which we placed all the SCL-90-R scales and time spent working in a week as outcomes of both workaholism and work engagement. The model showed an excellent fit to the data: $\chi^{2} / \mathrm{df}=.96, p=.47$; GFI $=$ $1.00 ; \mathrm{CFI}=1.00$; RMSEA $=.00,90 \% \mathrm{CI}=[.00-.06]$. Figure 1 depicts the structural model with standardized path estimates. In sum, except for working hours, all the internalizing and externalizing scales are predicted by both workaholism (positively) and work engagement (negatively). Moreover, about the psychopathology scales whose variance is explained the most by workaholism and work engagement, they are Obsessions (19\% of the variance), Anxiety, and Depression (17\% of the variance). The scales whose variance is explained the least are instead Hostility and Somatization (9\%). Finally, about the variance explained for the other scales: Psychoticism and Paranoid Ideation, 13\%; Interpersonal Sensitivity, 11\%; Phobic Anxiety, 10\%. Finally, Obsessive-Compulsive symptoms are the ones predicted more strongly by both workaholism $(\beta=.41, p<.001)$ and work engagement $(\beta=-.31, p<.001)$. 


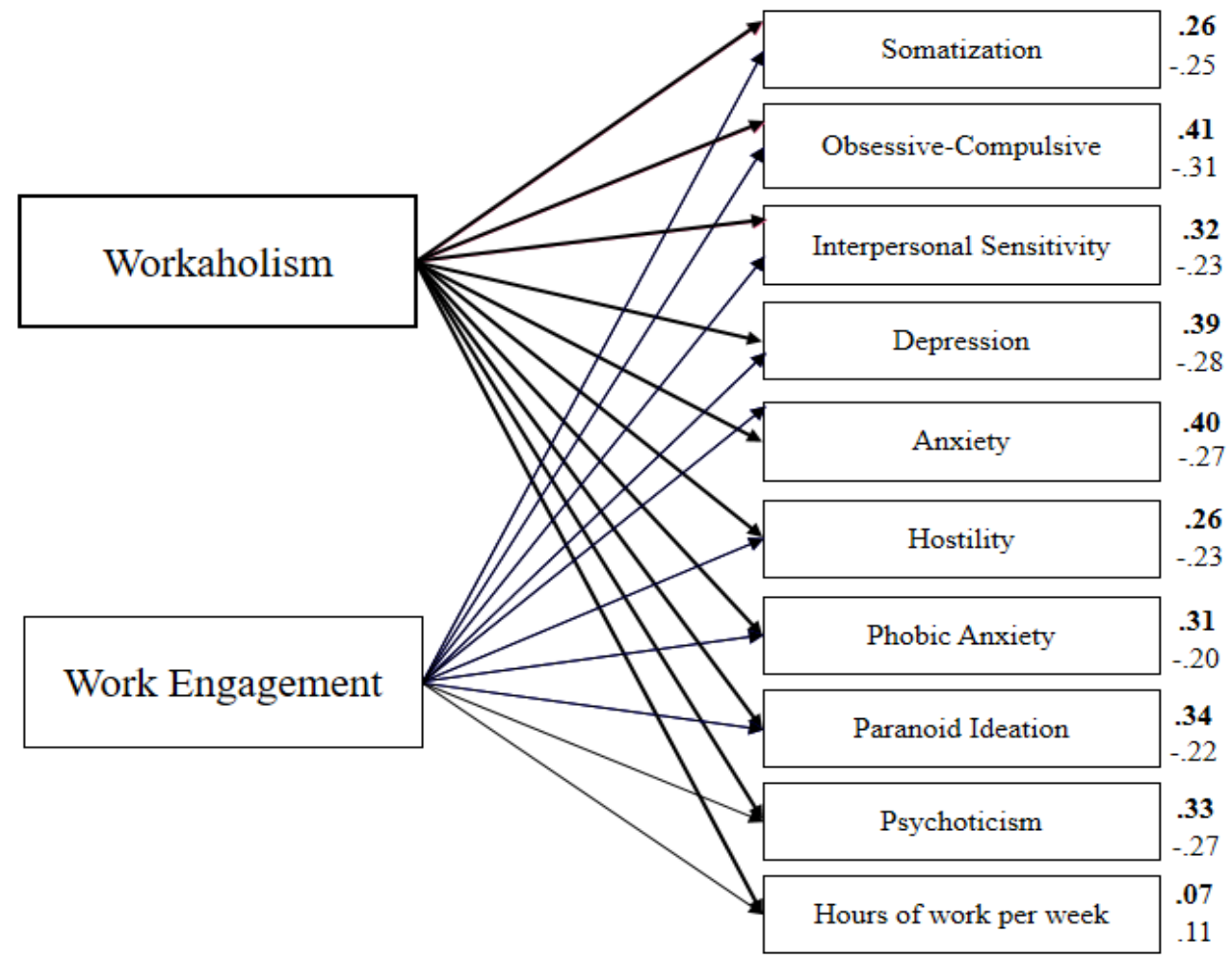

Figure no. 1. Structural model with standardized path estimates for psychopathology and working hours as outcomes of workaholism and work engagement $(n=324)$.

Note: Bold path estimates and lines $=$ Workaholism; Plain path estimates and lines $=$ Work Engagement; path estimates for Hours of work per week are not statistically significant; $\mathrm{p}<.001$ for all the other path estimates.

\subsection{Sensation Seeking and Internalizing and Externalizing Disorders as Antecedents of HWI}

In order to evaluate the role of psychopathology and sensation seeking as antecedents of HWI, we tested our second model on the second sample of workers $(n=366)$, in which all the SCL-90-R scales and SSS-V scales are antecedents of both workaholism and work engagement. The model showed a good fit to the data: $\chi^{2} / \mathrm{df}=2.99, p<.001 ; \mathrm{GFI}=.96$; CFI $=.98$; RMSEA $=.07,90 \% \mathrm{CI}=[.06-.09]$. However, the predictors explained just $11 \%$ of the variance in workaholism and $10 \%$ for work engagement. In line with this, there are few statistically significant predictors. More specifically, workaholism is predicted by Psychoticism $(\beta=.28, p=.005)$ only. Work Engagement, instead, is positively predicted by Somatization $(\beta=.21, p=.005)$, and negatively predicted by Depression $(\beta=-.40, p<.001)$ and Boredom Susceptibility $(\beta=-.13, p<.001)$. 


\subsection{High versus low levels of HWI: Differences in psychopathology and sensation seeking}

In order to analyze if there are differences in psychopathology and sensation seeking scores between workers with high and low levels of workaholism (and work engagement), we performed two MANOVAs. In the total sample $(n=690)$, using Loscalzo and Giannini's (2019a) cut-off scores, there are 165 workers $(23.9 \%)$ with high workaholism and 59 workers $(8.6 \%)$ with low workaholism. Moreover, for work engagement, 86 workers (12.5\%) have high work engagement, while 71 participants $(10.3 \%)$ have low work engagement. Though, even if all of these participants filled the SCL-90-R, just some of them filled the SSS-V.

About workaholism, we found that it has a multivariate statistically significant effect on psychopathology: $F(9,214)=4.45, p<.001, \eta^{2}=.16$. More specifically, follow-up ANOVAs highlighted statistically significant differences in all the SCL-90-R scales, with workers characterized by high workaholism scoring higher than the ones with low workaholism. About work engagement, we found again a multivariate statistically significant effect on psychopathology: $F(9,147)=3.65, p<.001, \eta^{2}=.18$, and statistically significant differences in all the SCL-90-R scales. More specifically, higher SCL-90-R scores characterize workers with low work engagement, as compared to the ones with high work engagement (Table 2 shows the results of the analyses). Finally, concerning sensation seeking, the MANOVAs did not show statistically significant differences for workaholism and work engagement.

Table no. 2. MANOVA. Psychopathology scales by low and high workaholism (WH) and Work Engagement (WE).

\begin{tabular}{|c|c|c|c|c|c|c|c|}
\hline SCL-90-R & & Level & $n$ & $M(S D)$ & $F^{\S}$ & $p$ & partial $\eta^{2}$ \\
\hline \multirow[t]{6}{*}{ Somatization } & WH & Low & 59 & $19.68(7.68)$ & 5.85 & .016 & .03 \\
\hline & & High & 165 & $23.06(9.71)$ & & & \\
\hline & & Total & 224 & $22.17(9.32)$ & & & \\
\hline & WE & Low & 71 & $23.10(8.50)$ & 7.35 & .007 & .05 \\
\hline & & High & 86 & $19.40(8.53)$ & & & \\
\hline & & Total & 157 & $21.07(8.69)$ & & & \\
\hline \multirow{6}{*}{$\begin{array}{l}\text { Obsessive- } \\
\text { Compulsive }\end{array}$} & WH & Low & 59 & $15.81(6.65)$ & 23.45 & $<.001$ & .10 \\
\hline & & High & 165 & $21.24(7.63)$ & & & \\
\hline & & Total & 224 & 19.81(7.75) & & & \\
\hline & WE & Low & 71 & $22.15(8.99)$ & 18.08 & $<.001$ & .10 \\
\hline & & High & 86 & $16.87(6.55)$ & & & \\
\hline & & Total & 157 & $19.26(8.16)$ & & & \\
\hline \multirow{6}{*}{$\begin{array}{l}\text { Interpersonal } \\
\text { Sensitivity }\end{array}$} & WH & Low & 59 & $12.71(5.43)$ & 18.21 & $<.001$ & .08 \\
\hline & & High & 165 & $16.87(6.73)$ & & & \\
\hline & & Total & 224 & 15.77(6.66) & & & \\
\hline & WE & Low & 71 & $17.39(6.63)$ & 19.09 & $<.001$ & .11 \\
\hline & & High & 86 & $13.42(4.74)$ & & & \\
\hline & & Total & 157 & $15.22(6.00)$ & & & \\
\hline \multirow[t]{4}{*}{ Depression } & WH & Low & 59 & $20.56(9.17)$ & 18.40 & $<.001$ & .08 \\
\hline & & High & 165 & $27.19(10.52)$ & & & \\
\hline & & Total & 224 & 25.44(10.58) & & & \\
\hline & WE & Low & 71 & $28.55(12.27)$ & 21.84 & $<.001$ & .12 \\
\hline
\end{tabular}




\begin{tabular}{|c|c|c|c|c|c|c|c|}
\hline SCL-90-R & & Level & $n$ & $M(S D)$ & $F^{\S}$ & $p$ & partial $\eta^{2}$ \\
\hline & & High & 86 & $20.81(8.39)$ & & & \\
\hline & & Total & 157 & 24.31(10.99) & & & \\
\hline \multirow[t]{6}{*}{ Anxiety } & WH & Low & 59 & $14.32(5.22)$ & 17.01 & $<.001$ & .07 \\
\hline & & High & 165 & $18.95(8.02)$ & & & \\
\hline & & Total & 224 & $17.73(7.65)$ & & & \\
\hline & WE & Low & 71 & $18.37(7.34)$ & 13.91 & $<.001$ & .08 \\
\hline & & High & 86 & $14.53(5.52)$ & & & \\
\hline & & Total & 157 & $16.27(6.67)$ & & & \\
\hline \multirow[t]{6}{*}{ Hostility } & WH & Low & 59 & $9.69(4.63)$ & 4.24 & .04 & .02 \\
\hline & & High & 165 & $11.15(4.67)$ & & & \\
\hline & & Total & 224 & $10.77(4.70)$ & & & \\
\hline & WE & Low & 71 & $11.42(3.94)$ & 12.71 & $<.001$ & .08 \\
\hline & & High & 86 & $9.15(4.00)$ & & & \\
\hline & & Total & 157 & $10.18(4.12)$ & & & \\
\hline \multirow[t]{6}{*}{ Phobic Anxiety } & WH & Low & 59 & $8.07(2.64)$ & 13.25 & $<.001$ & .06 \\
\hline & & High & 165 & $10.38(4.60)$ & & & \\
\hline & & Total & 224 & $9.77(4.29)$ & & & \\
\hline & WE & Low & 71 & $9.76(3.64)$ & 16.09 & $<.001$ & .09 \\
\hline & & High & 86 & 7.94(1.92) & & & \\
\hline & & Total & 157 & $8.76(2.96)$ & & & \\
\hline \multirow[t]{6}{*}{ Paranoid Ideation } & WH & Low & 59 & $9.88(4.15)$ & 16.77 & $<.001$ & .07 \\
\hline & & High & 165 & $12.86(5.00)$ & & & \\
\hline & & Total & 224 & $12.08(4.96)$ & & & \\
\hline & WE & Low & 71 & 13.99(5.09) & 16.50 & $<.001$ & .10 \\
\hline & & High & 86 & $10.88(4.47)$ & & & \\
\hline & & Total & 157 & $12.29(4.99)$ & & & \\
\hline \multirow[t]{6}{*}{ Psychoticism } & $\mathrm{WH}$ & Low & 59 & 12.81(5.13) & 21.33 & $<.001$ & .09 \\
\hline & & High & 165 & $17.12(6.46)$ & & & \\
\hline & & Total & 224 & $15.98(6.41)$ & & & \\
\hline & WE & Low & 71 & $16.93(7.04)$ & 13.39 & $<.001$ & .08 \\
\hline & & High & 86 & $13.56(4.40)$ & & & \\
\hline & & Total & 157 & 15.08(5.97) & & & \\
\hline
\end{tabular}

Note. ${ }^{\S}=$ for workaholism, $\mathrm{df}=1,224$; for work engagement, $\mathrm{df}=1,156$.

\subsection{Disengaged and Engaged workaholics: Differences in psychopathology and sensation seeking}

Finally, aiming to evaluate if there are differences in the psychopathology and sensation seeking scales between disengaged and engaged workaholics, we performed Mann-Whitney tests. The number of workers belonging to the two groups did not allow us to perform parametric analyses. More specifically, in the total sample, there are 6 disengaged workaholics $(.9 \%)$ and 35 engaged workaholics $(5.1 \%)$, and for sensation seeking there are even fewer: 3 and 18, respectively. About the other two types of worker suggested by Loscalzo and Giannini (2017a), in the total sample, there are 6 engaged workers (.9\%) and 16 detached workers $(2.3 \%)$. 
The results of Mann-Whitney tests highlighted that there are no statistically significant differences between disengaged and engaged workaholics on the SCL-90-R and SSS-V scales.

\section{Discussions}

The main aim of this paper is to shed light on the internalizing and/or externalizing nature of workaholism through the analysis of psychopathology as both an antecedent and an outcome of two types of Heavy Work Investment (HWI), that is workaholism and work engagement. Hence, we also include sensation seeking as an antecedent of HWI, since the literature showed that it is consistently associated with substance-related addictions, which are externalizing disorders.

First, looking at the results of the correlation analyses, we found preliminary evidence for the positive association between workaholism and both internalizing and externalizing disorders, and for the negative association between work engagement and psychopathology. Moreover, besides the negative correlation between work engagement and the Boredom Susceptibility scale of sensation seeking, there are no statistically significant correlations between HWI and sensation seeking. Finally, working hours do not correlate with workaholism, and the positive correlation with work engagement is very low $(r=.08)$.

Next, we analyzed further the relationship between HWI, psychopathology, sensation seeking, and working hours through two path analysis models, which allow detection of the predictive power of the variables while controlling for the effect of all the other variables included in the model.

The first model tested the role of HWI in predicting psychopathology and working hours. The results showed that workaholism positively predicts all the nine psychopathology scales included in the model. The highest beta values are for three internalizing symptoms, namely Obsessive-Compulsive $(\beta=.41 ; p<.001)$, Anxiety $(\beta=.40 ; p<.001)$, and Depression $(\beta=.39 ; p<.001)$. However, all the $\beta$ values are good, ranging between .26 (Somatization and Hostility) and .41. Hence, in line with previous studies (e.g., Andreassen, et al., 2007; Bartcazc and Ogińska-Bulik, 2012; Wojdylo, et al., 2013), we found support for the assertion that workaholism predicts higher levels of somatization, anxiety, and depression. Moreover, we extended previous findings by highlighting that workaholism predicts other internalizing symptoms: Obsessive-Compulsive symptoms, Interpersonal Sensitivity (or social anxiety), and Phobic Anxiety. Moreover, we showed that workaholism predicts externalizing symptoms as well: Hostility, Paranoid Ideation, and Psychoticism. This result might explain the association between workaholism and aggressive behaviors in the workplace (Balducci, et al., 2012; Loscalzo and Giannini, 2017a).

Moreover, concerning work engagement, we found that it negatively predicts all the internalizing and externalizing symptoms, providing further support to the few studies that previously showed that it is associated with better mental health (e.g., Andreassen, et al., 2007; Haar and Roche, 2013). More specifically, we extended previous studies by analyzing both internalizing and externalizing symptoms.

Finally, the model showed that neither workaholism nor work engagement predicts working hours. More specifically, the beta values are positive for both the predictors (for work engagement, the value is of .11); though, they do not reach statistical significance. The 
literature on this topic is not consistent. However, we speculate that the lack of relationship might be because time spent working is not a good indicator of HWI. The discriminant between working and overworking might rely instead upon the effort put into the work, in the time spent thinking to work-related issues outside working hours, and in the time spent working outside the hours established by the contract. Hence, future studies could deepen the analysis of the relationships between working hours and HWI by asking other specific questions concerning working time.

Based on the results of this first path model, we suggest in line with Loscalzo and Giannini (2017a) that it is of paramount importance to develop (and test) preventive interventions to implement in organizations aimed at reducing workaholism and favoring work engagement. Workers with high levels of workaholism are more at risk of developing both internalizing and externalizing symptoms, with negative consequences not just for the individual, but also for his/her family and organization. Work engagement, instead, leads to less psychological symptoms.

Next, we tested a second model in which HWI is predicted by psychopathology and sensation seeking. These analyses showed that psychopathology and sensation seeking do not explain a large percentage of variance in workaholism $(11 \%)$ and work engagement $(10 \%)$. In line with this, only one scale predicts workaholism, and it is Psychoticism $(\beta=.28 ; p=.005)$. Work engagement, instead, is predicted by Somatization $(\beta=.21$; $p=.005)$, Depression $(\beta=-.40 ; p<.001)$ and Boredom Susceptibility $(\beta=-.13 ; p=.022)$.

In literature, few studies analyzed psychopathology as an antecedent of workaholism, and they showed that ADHD, which is a neurodevelopment disorder (DSM-5; APA, 2013), positively predicts workaholism. Instead, depression and obsessive-compulsive symptoms do not predict workaholism or predict it with very low beta values (Andreassen, et al., 2016; Atroszko, et al., 2018). Finally, Andreassen, et al. (2016) found that anxiety predicts workaholism with a $\beta$ value of .17. Our results, in line with Andreassen, et al. (2016) and Atroszko, et al. (2018), showed that Depression and Obsessive-Compulsive symptoms do not predict workaholism. However, in contrast with Andreassen, et al. (2016), neither Anxiety predicts workaholism. In our study, the $\beta$ value for this scale is .14 ; though, it is not statistically significant. In addition, our study extends previous studies by highlighting that other internalizing and externalizing symptoms do not predict workaholism, except for Psychoticism. Also, sensation seeking, which is a personality trait linked to substance addictions (i.e., externalizing disorders), does not predict workaholism.

In light of the results arisen by this second path model, we suggest that Loscalzo and Giannini's (2017a) proposal of taking a step back in the conceptualization of workaholism in order to shed light on its real nature is worthwhile being pursued by future studies. Indeed, we did not find evidence for psychopathology as an antecedent of workaholism, as the only predictor is Psychoticism, which is a scale evaluating symptoms like delusions and social isolation; hence, they are symptoms which might be linked to Cluster A - Personality Disorders, such as Schizoid Personality Disorder. A detachment from social relationships characterizes this personality disorder, and it might be associated with work impairment (if the job requires social relations) or high-level functioning if the person can work in isolation. Also, there might be psychotic episodes, especially due to stress (APA, 2013). Hence, also personality disorders should be taken into account for a proper conceptualization of workaholism. In fact, in our study, neither internalizing nor externalizing disorders predict workaholism, except for Psychoticism that is a scale that 
might be related mostly to personality disorders than to psychopathological disorders. Therefore, we speculate that besides considering the internalizing and/or externalizing nature of workaholism, scholars should also consider the possibility of conceptualizing workaholism as a work-related declination of a personality disorder. In line with this, Innanen, Tolvanen, and Salmela-Aro (2014) and Mäkikangas, et al. (2013) showed that workaholism generally represents a stable pattern, which is congruent with the definition of personality disorders (APA, 2013). In sum, we confirm the need to avoid an a-priori addiction approach for the study of workaholism and to take into account internalizing symptoms as well, also in light of the lack of predictive power on workaholism by sensation seeking, which is a variable linked to substance addictions (even if it should be noted that the relationship with gambling disorder is not consistent). Though, based on the present findings, we also suggest taking into account the possibility that workaholism might be better explained referring to personality disorders. Among personality disorders, the present findings suggest considering the ones belonging to Cluster A (including Schizoid Personality Disorder). However, another possibility is related to the Obsessive-Compulsive Personality Disorder, which includes in the diagnostic criteria some workaholism features, such as excessive dedication to work and productivity at the expense of leisure and friendship (APA, 2013). However, more studies are needed in order to shed light on the real nature of workaholism

The results of the second path model are also interesting concerning work engagement. It is predicted negatively by Depression. Though, it is predicted positively by Somatization. We speculate that overworking might be a strategy for coping with somatization symptoms, that in turn (as shown by the first path model) leads to lower somatization symptoms. Hence, workers with high levels of somatization might use overworking as a strategy to reduce their attention to somatic symptoms, which consecutively might disappear thanks to this positive form of HWI. Though, further studies are needed in order to shed light on this aspect.

Regarding sensation seeking, Boredom Susceptibility is a negative predictor of work engagement. This is in line with the content of this scale, as it evaluates the preference for new and uncommon experiences. Since engaged workers spent a lot of time and effort in doing their work, we might assume that they have good levels of boredom tolerability, which allows them to work a long time on the same task.

Finally, we analyzed if there are differences in the psychopathology scales between workers with high and low levels of workaholism/work engagement, as well as between disengaged and engaged workaholics. In line with Matsudaira, et al., (2013), Andreassen et al. (2016), and Atroszko, et al. (2018), we found that workers with high workaholism are characterized by higher levels of psychopathology symptoms in all the scales, as compared to workers with low workaholism. Moreover, we extended previous studies by pointing out that people with high work engagement have lower levels of psychopathology than workers with low work engagement. Hence, interventions intended to favor workers' well-being should have the aim of increasing work engagement, as it is associated with better mental health. Finally, there are no differences in sensation seeking scales neither for workaholism nor for work engagement. Hence, we re-affirm that sensation seeking is not a variable related to HWI, at least based on our first study on this topic. This also suggests that the addiction model does not seem fully adequate to describe workaholism. Though, future 
studies should further analyze the role of sensation seeking in workaholism, also in light of the inconsistent findings on sensation seeking and gambling disorder.

Finally, concerning the different types of workaholics, we did not find any differences in the psychopathology and sensation seeking scales. Though, this is in line with Loscalzo and Giannini (2019b), who did not find a difference in psychological distress (as evaluated through a scale measuring anxiety, depression, and stress) between disengaged and engaged studyholics. However, Loscalzo and Giannini (2019b) found some differences between the two types of studyholics on some other outcomes (for Studyholism, see Loscalzo and Giannini, 2017b, 2018a, 2018b). Hence, we conclude that it is essential to differentiate between the different types of workaholics aiming to understand if there are differences in the relationships with the same variables. However, concerning internalizing and externalizing symptoms specifically, we can assume that work engagement does not protect workaholics against high psychological impairment since engaged workaholics do not have better mental health as compared to disengaged workaholics. Therefore, preventive and clinical interventions aimed at favoring well-being in workaholics should target work engagement, aiming to increase it, but they should also favor a reduction in workaholism.

The main limit of this study is due to the scale we used for evaluating sensation seeking, since it has not been validated in the Italian adult population, even if already used with Italian youths. Moreover, the preliminary analyses performed on the current sample showed that most of the scales do not have satisfactory internal reliability. Hence, the results about sensation seeking should be read cautiously, and future studies should further analyze the role of sensation seeking in HWI. Moreover, even if the sample is large and heterogeneous concerning the city in which the workers live, half of the participants live in Central Italy. Finally, we used a self-report scale for measuring psychopathology that does not allow to check for "faking bad" answers. Future studies could use a diagnostic interview to analyze further the role of Psychoticism (and, potentially, personality disorders), through diagnostic clinical interviews.

Despite these limitations, this study has the main merit of being the first research to analyze thoroughly internalizing and externalizing disorders as both antecedents and outcomes of workaholism and work engagement through a widely used self-report scale. In fact, previous studies mainly focused on subjective health complaints (which might be considered somatization), depression, and anxiety as outcomes of workaholism. Also, it is the first study to analyze the role of sensation seeking as a potential antecedent of workaholism and work engagement. In addition, the participants are balanced for gender and heterogeneous concerning the type of work and contract. Finally, the results of our analyses gave valuable insights for preventive purposes. For example, they highlighted the negative impact of workaholism on mental health and that high work engagement does not protect workaholics from having high levels of psychological symptoms. Hence, it is imperative to implement interventions aimed at reducing workaholism since fueling work engagement might not be enough. Finally, this study gave insights at a theoretical level, as suggesting that we should also take into account the possibility that workaholism is the manifestation at work of a personality disorder, instead of an internalizing and/or externalizing disorder. 


\section{Conclusions}

The main aim of this study was to shed light on the role of internalizing and externalizing disorders as antecedents and outcomes of two types of Heavy Work Investment, that is workaholism and work engagement. The results highlighted that workaholism predicts higher internalizing and externalizing symptoms, while work engagement predicts lower symptoms. Moreover, workaholism is predicted by Psychoticism only, suggesting that workaholism might be conceptualized as the declination at work of a personality disorder, such as Schizoid or Obsessive-Compulsive Personality Disorder. Also, sensation seeking does not predict workaholism, providing further support for the need to analyze other explanations as compared to the behavioral addiction one. Work engagement, instead, is positively predicted by Somatization, suggesting that this type of Heavy Work Investment might be fueled by somatic complaints as a coping strategy with these symptoms. Finally, while there are differences in psychopathology between workers with high and low workaholism (and work engagement), there are no differences between disengaged and engaged workaholics, suggesting that a high level of work engagement does not protect engaged workaholics from high psychological impairment.

This study has important implications for preventive purposes, suggesting that both workaholism and work engagement should be targeted aiming at reducing psychological impairment in workers. Moreover, it has implications for the theorization and definition of the construct of workaholism.

\section{Acknowledgment}

We thank Dr. Giulia Romei for her support in data collection.

\section{References}

Adams, Z.W., Kaiser, A.J., Lynam, D.R., Charnigo, R.J. and Milich, R., 2012. Drinking motives as mediators of impulsivity-substance use relation: Pathways for negative urgency, lack of premeditation, and sensation seeking. Addictive Behaviors, 37(7), pp.848-855.

Allcock, C.C. and Grace, D.M., 1988. Pathological gamblers are neither impulsive nor sensation-seekers. Australasian Psychiatry, 22(3), pp.307-311.

American Psychiatric Association, 2013. Diagnostic and Statistical Manual of Mental Disorders. Fifth Edition ed. [online] American Psychiatric Association. Available at: <https://psychiatryonline.org/doi/book/10.1176/appi.books.9780890425596> [Accessed 5 June 2020].

Andreassen, C.S., Griffiths, M.D., Hetland, J. and Pallesen, S., 2012. Development of a work addiction scale. Scandinavian Journal of Psychology, 53(3), pp.265-272.

Andreassen, C.S., Griffiths, M.D., Sinha, R., Hetland, J. and Pallesen, S., 2016. The relationships between workaholism and symptoms of psychiatric disorders: A largescale cross-sectional Study. PLoS ONE, 11(5), p. e0152978.

Andreassen, C.S., Hetland, J., Molde, J. and Pallesen, S., 2011. 'Workaholism' and potential outcomes in well-being and health in a cross-occupational sample. Stress and Health, 27(3), pp.e209-e214. 
Andreassen, C.S., Pallesen, S. and Trosheim, T., 2018. Workaholism as a mediator between work-related stressors and health outcomes. International Journal of Environmental Research and Public Health, 15(1), p. e73.

Andreassen, C.S., Ursin, H. and Eriksen, H.R., 2007. The relationship between strong motivation to work, "workaholism", and health. Psychology and Health, 22(5), pp.615-629.

Atroszko, P.A., Pallesen, S., Griffiths, M.D. and Andreassen, C.S., 2017. Work addiction in Poland: Adaptation of the Bergen Work Addiction Scale and relationship with psychopathology. Health Psychology Report, 5(4), pp.345-355.

Axtell, C., Wall, T., Stride, C., Pepper, K., Clegg, C., Gardner, P. and Bolden, R., 2002. Familiarity breeds content: The impact of exposure to change on employee openness and well-being. Journal of Occupational and Organisational Psychology, 75, pp.217-231.

Balducci, C., Cecchin, M., Fraccaroli, F. and Schaufeli, W.B., 2012. Exploring the relationship between workaholism and workplace aggressive behaviour: The role of job related emotion. Personality and Individual Differences, 53(5), pp.629-634.

Bartcazk, M. and Ogińska-Bulik, N., 2012. Workaholism and mental health among Polish academic workers. International Journal of Occupational Safety and Ergonomics, 18(1), pp.3-13.

Beck, A.T., Ward, C.H., Mendelson, M., Mock, J. and Erbaugh, J., 1961. An inventory for measuring depression. Archives of General Psychiatry, 4(6), pp.53-63.

Blaszczynski, A.P., Wilson, A.C. and McConaghy, N., 1986. Sensation Seeking and pathological gambling. British Journal of Addiction, 81(3), pp.113-117.

Bonnaire, C., Lejoyeux, M. and Dardennes, R., 2004. Sensation Seeking in a French population of pathological gamblers: Comparison with regular and non gamblers. Psychological Reports, 94(3 suppl), pp.1361-1371.

Breen, R.B. and Zuckerman, M., 1999. 'Chasing' in gambling behavior: Personality and cognitive determinants. Personality and Individual Differences, 27(6), pp.1097-1111.

Byrne, B.M., 2001. Structural equation modeling with AMOS: Basic concepts, applications, and programming. Mahwah, NJ: Lawrence Erlbaum Associates.

Crawford, A.M., Pentz, M.A., Chou, C.-P., Li, C. and Dwyer, J.H., 2003. Parallel developmental trajectories of sensation seeking and regular substance use in adolescents. Psychology of Addictive Behaviors, 17(3), pp.179-192.

Coventry, K.R. and Brown, R.I.F., 1993. Sensation seeking, gambling and gambling addictions. Addiction, 88(4), pp.541-554.

Derogatis, L.R., 1994. Symptom checklist-90-R, SCL-90-R: Administration, scoring and procedures manual. Minneapolis, USA: National Computer Systems.

Eriksen, H.R., Ihlebæk, C. and Ursin, H., 1999. A scoring system for subjective health complaints (SHC). Scandinavian Journal of Public Health, 27(1), pp.63-72.

Ersche, K.D., Turton, A.J., Pradhan, S., Bullmore, E.T. and Robbins, T.W., 2015. Drug addiction endophenotypes: Impulsive versus Sensation-Seeking personality traits. Biological Psychiatry, 68(8), pp.770-773. 
Foa, E.B., Huppert, J.D., Leiberg, S., Langner, R., Kichic, R., Hajcak, G. and Salkovskis, P.M., 2002. The Obsessive-Compulsive Inventory: Development and validation of a short version. Psychological Assessment, 14(4), pp.485-496.

Fortune, E.E., and Goodie, A.S., 2010. The relationship between pathological gambling and Sensation Seeking: The role of subscale scores. Journal of Gambling Studies, 26(3), pp.331-346.

Giannini, M. and Loscalzo, Y. (in press). Sensation seeking. In: B. J. Carducci, C. S. Nave, D. Saklofske, C. Stough, A. M., Di Fabio (Eds.), The Wiley Encyclopedia of Personality and Individual Differences: Volume III (pp.1463-1467). John Wiley \& Sons Ltd.

Goldberg, D.P., and Hillier, V.F., 1979. A scaled version of the general health questionnaire. Psychological Medicine, 9(1), pp.139-145.

Haare, J. and Roche, M., 2013. Three-way interaction effects of workaholism on employee well-being: Evidence from blue-collar workers in New Zealand. Journal of Management and Organization, 19(2), pp.134-149.

Hittner, J.B. and Swickert, R., 2006. Sensation Seeking and alcohol use: A meta-analytic review. Addictive Behaviors, 31(8), pp.1383-1401.

Hu, L. and Bentler, P.M., 1999. Cutoff criteria for fit indexes in covariance structure analysis: Conventional criteria versus new alternatives. Structural Equation Modeling, 6(1), pp.1-55.

Innanen, H., Tolvanen, A. and Salmela-Aro, K., 2014. Burnout, work engagement and workaholism among highly educated employees: Profiles, antecedents and outcomes. Burnout Research, 1(1), pp.38-49.

Jaffe, L.T. and Archer, R.P., 1987. The prediction of drug use among college students from MMPI, MCMI, and Sensation Seeking scales. Journal of Personality Assessment, 51(2), pp.243-253.

Kardefelt-Winther, D., 2015. Commentary on: Are we overpathologizing everyday life? A tenable blueprint for behavioral addiction research. Problems with atheoretical and confirmatory research approaches in the study of behavioral addictions. Journal of Behavioral Addictions, 4(3), pp.126-129.

Kessler, R.C., Adler, L., Ames, M., Demler, O., Faraone, S., Hiripi, E, Howes, M. J., Jin, R., Secnik, K., Spencer, T., Ustun, T. B. and Walters, E.E., 2005. The World Health Organization adult ADHD self-report scale (ASRS). Psychological Medicine, 35(2), pp.245-256.

Keyes, K.M., Jager, J., Hamilton, A., O'Malley, P.M., Miech, R. and Schulenberg, J.E., 2015. National multi-cohort time trends in adolescent risk preference and the relation with substance use and problem behavior from 1976 to 2011. Drug and Alcohol Dependence, 155, pp.267-274.

Kuley, N.B. and Jacobs, D.F., 1988. The relationship between dissociative-like experiences and sensation seeking among social and problem gamblers. Journal of Gambling Behaviors, 4, pp.197-207.

Linden-Carmichael, A.N., Stamates, A.L., Sheehan, B.E. and Lau-Barraco, C., 2016. Molly users versus non users in a sample of college alcohol drinkers: Differences in substancerelated harms and sensation seeking. Substance Abuse, 37, pp.474-479. 
Loscalzo, Y., and Giannini, M., 2017a. Clinical conceptualization of workaholism: A comprehensive model. Organizational Psychology Review, 7(4), pp.306-329.

Loscalzo, Y. and Giannini, M., 2017b. Studyholism or Study Addiction? A comprehensive model for a possible new clinical condition, In: A. M. Columbus (Ed.). Advances in Psychological Research (pp.19-37). New York: Nova Publisher.

Loscalzo, Y. and Giannini, M., 2018a. Problematic overstudying: Studyholism or Study Addiction? Commentary on: Ten myths about work addiction. Journal of Behavioral Addictions, 7(4), pp.867-870.

Loscalzo, Y. and Giannini, M., 2018b. Response to: Theoretical and methodological issues in the research on study addiction with relevance to the debate on conceptualising behavioural addictions: Atroszko (2018). Psychiatria i Psychologia Kliniczna, 18(4), pp.426-430.

Loscalzo, Y. and Giannini, M., 2019a. What type of worker are you? Work-related Inventory (WI-10): A comprehensive instrument for the measurement of workaholism. WORK: A Journal of Prevention, Assessment \& Rehabilitation, 62(3), pp.383-392.

Loscalzo, Y. and Giannini, M., 2019b. Heavy Study Investment in Italian College student. An analysis of Loscalzo and Giannini's (2017) Studyholism comprehensive model. Frontiers in Psychiatry, 10, p.489.

Mäkikangas, A., Schaufeli, W., Tolvanen, A. and Feldt, T., 2013. Engaged managers are not workaholics: Evidence from a longitudinal person-centered analysis. Journal of Work and Organizational Psychology, 29(3), pp.135-143.

Matsudaira, K., Shimazu, A., Fujii, T., Kubota, K., Sawada, T, Kikuchi, N. and Takahasi, M., 2013. Workaholism as a Risk Factor for Depressive Mood, Disabling Back Pain, and Sickness Absence. PLoS ONE, 8(9), p. e75140.

Meil, W.M., LaPorte, D.J., Milles, J.A., Sesti, A.N., Collings, S.M. and Stiver, A.G., 2016. Sensation seeking and executive deficits in relation to alcohol, tobacco, and marijuana use frequency among university students: Value of ecologically based measures. Addictive Behaviors, 62, pp.135-144.

Miles, D.R., van den Bree, M.B., Gupman, A.E., Newlin, D.B., Glantz, M.D. and Pickens, R.W., 2001. A twin study on sensation seeking, risk taking behavior and marijuana use. Drug and Alcohol Dependence, 62(1), pp.57-68.

Mullarkey, S., Wall, T.D., Warr, P.B., Clegg, C.W. and Stride, C.B., 1999. Measures of job satisfaction, mental health and job-related well-being. A bench-marking manual. Sheffield: Institute of Work Psychology.

Müller, K.W., Dreier, M., Beutel, M.E. and Wölfling, K., 2016. Is Sensation Seeking a correlate of excessive behaviors and behavioral addictions? A detailed examination of patients with Gambling Disorder and Internet Addiction. Psychiatry Research, 242, pp.319-325.

Nie, Y. and Sun, H., 2016. Why do workaholics experience depression? A study with Chinese University teachers. Journal of Health Psychology, 21(10), pp.2339-2346.

Powell, J. and Hardoon, K., 1999. Gambling and risk taking behaviors among university students. Substance Use and Misuse, 34(8), pp.1167-1184.

Reeve, B.B., Hays, R.D., Bjorner, J.B., Cook, K.F., Crane, P.K., Teresi, J.A., Thissen, D., Revicki, D.A., Weiss, D.J., Hambleton, R.K., Liu, H., Gershon, R., Reise, S.P., Lai, J. 
and Cella, D., 2007. Psychometric Evaluation and Calibration of Health-Related Quality of Life Item Banks: Plans for the Patient-Reported Outcomes Measurement Information System (PROMIS). Medical Care, 45(Suppl 1), pp.S22-S31.

Robinson, B.E., 1999. The work addiction risk test: development of a tentative measure of workaholism. Perceptual and Motor Skills, 88(1), pp.199-210.

Rogers, A.A., Elam, K.K., Chassin, L., Sternber, A. and Bui, L., 2018. Proximal and distal effects of sensation seeking and parenting environments on alcohol use trajectories from early adolescence to early adulthood. Journal of Youth and Adolescence, 47(10), pp.2206-2219.

Saez-Abad, C. and Bertolin-Guillen, J.M., 2008. Personality traits and disorders in pathological gamblers versus normal controls. Journal of Addictive Diseases, 27(1), pp. 33-40.

Schaufeli, W.B., Salanova, M., Gonzàlez-Roma, V. and Bakker, A.B., 2002. The measurement of engagement and burnout: A two-sample confirmatory factor analytic approach. Journal of Happiness Studies, 3, pp.71-92.

Schaufeli, W.B., Shimazu, A and Taris, T.W., 2009. Being driven to work excessively hard: The evaluation of a two-factor measure of workaholism in the Netherlands and Japan. Cross-Cultural Research, 43(4), pp.320-348.

Schaufeli, W.B., Taris, T.W. and van Rhenen, W., 2008. Workaholism, Burnout, and Work Engagement: Three of a king or three different kinds of employee well-being? Applied Psychology: An International Review, 57(2), pp.173-203.

Shimazu, A., Schaufeli, W.B., Kubota, K., Watanabe, K. and Kawakami, N., 2018. Is too much work engagement detrimental? Linear or curvilinear effects on mental health and job performance. Plos One, 13(2), p. e0208684.

Snir, R. and Harpaz, I., 2012. Beyond workaholism: Towards a general model of heavy work investment. Human Resource Management Review, 22(3), pp.232-243.

Spagnoli. P., Balducci, C., Scafuri Kovalchuk, L., Maiorano, F. and Buono, C., 2018. Are engaged workaholics protected against job-related negative affect and anxiety before sleep? A study of the moderating role of gender. International Journal of Environmental Research and Public Health, 15(9), p. e1996.

Spence, J.T and Robbins, A.S., 1992. Workaholism: Definition, measurement, and preliminary results. Journal of Personality Assessment, 58(1), pp.160-178.

Stautz, K. and Cooper, A., 2013. Impulsivity-related personality traits and adolescent alcohol use: A meta-analytic review. Clinical Psychology Review, 33(4), pp.574-592.

Terluin, B., Van Rhenen, W., Schaufeli, W.B. and de Haan, M., 2004. The FourDimensional Symptom Questionnaire (4DSQ): Measuring distress in a working population. Work and Stress, 18(3), pp.187-207.

Tonetti, L., Adan, A., Caci, H., De Pascalis, V., Fabbri, M. and Natale, V., 2010. Morningness-eveningness preference and sensation seeking. European Psychiatry, 25(2), pp.111-115.

Ware, J.E. Jr and Sherbourne, C.D., 1992. The MOS 36-item short-form health survey (SF-36): I. Conceptual framework and item selection. Medical Care, 30(6), pp.473-483. 
Wojdylo, K., Baumann, N., Buczny, J., Owens, G. and Kuhl, J., 2013. Work Craving: A conceptualization and measurement. Basic and Applied Social Psychology, 35(6), pp.547-568.

Wojdylo, K., Baumann, N., Fischbach, L. and Engeser, S., 2014. Live to work or love to work: Work craving and work engagement. Plos One, 9(10), p. e106379.

Zigmond, A.S. and Snaith, R.P., 1983. The Hospital Anxiety and Depression Scale. Acta Psychiatrica Scandinava, 67(6), pp.361-370.

Zhornitsky, S., Rizkallah, É., Pampoulova, T., Chiasson, J.P., Lipp, O., Stip, E. and Potvin, S., 2012. Sensation-seeking, social anhedonia, and impulsivity in substance use disorder patients with and without schizophrenia and in non-abusing schizophrenia patients. Psychiatry Research, 200(2-3), pp.237-241.

Zuckerman, M., 1994. Behavioral expressions and biosocial bases of sensation seeking. New York: Cambridge University Press.

Zuckerman, M., Eysenck, S.B.G. and Eysenck, H.J., 1978. Sensation seeking in England and America: cross-cultural, age, and sex comparisons. Journal of Consulting and Clinical Psychology, 46(1), pp.139-149.

Zung, W. (1986). Zung self-rating depression scale and depression status inventory. In: N. Sartorius \& T. A. Ban (Eds.). Assessment of Depression (pp.221-231). Berlin, Heidelberg: Springer-Verlag. 